\title{
Glucose-Insulin Therapy, Plasma Substrate Levels and Cardiac Recovery After Cardiac Ischemic Events
}

\author{
C. J. Zuurbier • H. B. Van Wezel
}

Published online: 12 February 2008

(C) The Author(s) 2008

\begin{abstract}
Introduction The potential usefulness of glucose-insulin therapy relies to a large extent on the premise that it prevents hyperglycemia and hyperlipidemia following cardiac ischemic events.

Methods In this review we evaluate the literature concerning plasma glucose and free fatty acids levels during and following cardiac ischemic events.

Results The data indicate that hyperlipidemia and hyperglycemia most likely occur during acute coronary ischemic syndromes in the conscious state (e.g. acute myocardial infarction) and less so during reperfusion following $\mathrm{CABG}$ reperfusion. This is in accordance with observations that glucose-insulin therapy during early reperfusion post CABG may actually cause hypolipidemia, because substantial hyperlipidemia does not appear to occur during that stage of cardiac surgery.

Discussion Considering recent data indicating that hypolipidemia may be detrimental for cardiac function, we propose that free fatty acid levels during reperfusion post CABG with the adjunct glucose-insulin therapy need to be closely monitored.

Conclusion From a clinical point of view, a strategy directed at monitoring and thereafter maintaining plasma substrate levels in the normal range for both glucose (4-6 mM) and FFA $(0.2-0.6 \mathrm{mM})$ as well as stimulation of glucose oxidation, promises to be the most optimal metabolic reperfusion treatment following cardiac ischemic episodes. Future (preclinical and subsequently clinical)
\end{abstract}

C. J. Zuurbier $(\bowtie) \cdot$ H. B. Van Wezel

Department of Anesthesiology, Academic Medical Center,

University of Amsterdam,

Amsterdam, The Netherlands

e-mail: c.j.zuurbier@amc.uva.nl investigations are required to investigate whether the combination of glucose-insulin therapy with concomitant lipid administration may be beneficial in the setting of reperfusion post $\mathrm{CABG}$.

Key words glucose-insulin therapy · free fatty acid . ischemia $\cdot$ reperfusion $\cdot \mathrm{CABG}$

\section{Introduction}

Ever since the introduction of glucose-insulin-potassium therapy in the setting of cardiac ischemic diseases [1], this technique has gone through alternating periods of varying attention. Although originally devised to prevent intramyocardial hypokalemia during ischemia and reperfusion, the therapy is nowadays mainly advocated to reduce hyperglycemia and hyperlipidemia which have been deemed to be present during the reperfusion period.

The first part of this review entails a critical appraisal of the literature concerning plasma substrate concentrations following reperfusion of ischemic cardiac events. We hope to convince the reader that, although plasma levels of free fatty acids (i.e., non-esterified fatty acids) and glucose may be elevated during reperfusion, this certainly is not always observed. Factors affecting substrate availability are highly influenced by the specific standard operation protocols used by the hospital (protocols for fasting, anesthesia techniques, heparin use, inotropic therapy), the anxiety of the organism (conscious versus anaesthetized) and the medical characteristics of the patient. The availability of substrates in the blood stream is a major determinant of myocardial metabolic activity. Metabolic treatment of the ischemic heart during reperfusion, therefore, can only be successful when it is based on accurate knowledge concerning the pre- 
treatment (=baseline) levels of circulating substrates of the patient.

The second part of this review is directed at how glucose-insulin therapy may affect substrate availability during reperfusion and how these changes may affect cardiac recovery following an ischemic episode through specific alterations in cardiac metabolism. From a clinical point of view, a strategy directed at keeping plasma substrate levels within the normal range (thus preventing both hyperand hypoglycemia and hyper-and hypolipidemia) and at stimulation of glucose oxidation seems to hold the most promise for optimal treatment of the heart following cardiac ischemic episodes.

\section{Plasma substrate availability during cardiac ischemic events}

\section{Clinical factors affecting substrates}

In the healthy, fed individual, blood glucose levels range between 4-6 $\mathrm{mM}(70-110 \mathrm{mg} / 100 \mathrm{dl})$ and free fatty acid (FFA) levels between 0.2-0.6 mM. However, in the perioperative condition considerable changes in these substrate levels may occur as a consequence of the specific operation protocol. Patients scheduled for elective cardiac operations are usually requested to refrain from food intake $12-24 \mathrm{~h}$ before the operation. This fasting procedure results in low insulin levels (removing insulin-inhibition of lipoprotein lipase (LPL)), increased FFA concentration and decreased glucose concentration [2,3]. The next confounding factor is the type of anesthetic regimen chosen. Many anesthetics differently affect plasma glucose and insulin levels, with minor effects on plasma FFA. We recently showed that, while pentobarbital and sufentanil-propofol were without effect on plasma glucose concentration, volatile anesthetics and $\alpha_{2}$-agonists (e.g. xylazine, medetomidine) resulted in hyperglycemia and thus deregulation of glucose homeostasis [4]. Both anesthesia techniques based on the use of either opioids or volatile anesthetics are frequently used for the anesthetic management of patients undergoing cardiac operations. Furthermore, although cardiac operations necessitate the use of the anti-coagulation agent heparin, it has long been known that heparin can result in a several-fold increase in plasma FFA levels by inducing the release of hepatic and endothelial-bound LPL [5, 6]. This heparineffect is often only present during the early reperfusion phase following by-pass operations, because heparin is usually quickly antagonized upon termination of the by-pass. Less well-known is the ongoing lipolysis in the sample due to the presence of this detached LPL, especially after the in vivo administration of heparin $[7,8]$. Without special precautions, e.g. inhibition of ex vivo lipolysis with a potent lipoprotein lipase inhibitor [9], plasma FFA may be substantially overestimated by the lab. We believe that this aspect has often been neglected, resulting in an overestimation of FFA during conditions of heparin administration (usually early reperfusion). In addition, acute myocardial infarction in the conscious state and post-ischemic reperfusion are characterized by high levels of catecholamines from endogenous sources and/or from the inotropic support given by the clinician $[10,11]$. These high levels of catecholamines have also been hypothesized to inhibit insulin secretion and to activate lipolysis of adipose tissue resulting in increased plasma FFA [12, 13].

Therefore, it appears that, in the peri-operative patient, the standard clinical treatment and applied biochemical determination of especially FFA are critical issues when reviewing substrate levels during reperfusion. Each surgical/ anesthesia team should determine the metabolic profile associated with its perioperative protocols to determine if improvement in cardiac function may be anticipated with the use of metabolic support. To illustrate this important point, it is shown in Table 1 that certainly not all studies report increased FFA and glucose levels following ischemia. The table indicates that FFA levels are most likely to be elevated during conditions of acute coronary syndromes in the conscious state (e.g. acute MI, [14-16]). During conditions of actual reperfusion, such as following PTCA after acute MI [16-20] or after less severe ischemia, such as following CABG in the anaesthetized condition [21-24], FFA levels are less likely to be elevated.

It should be noted that, although elevated FFA levels have long been viewed as a risk factor, there is evidence that elevated glucose levels are also associated with increased risk $[25,26]$. However, the table indicates that hyperglycemia is certainly not always present upon reperfusion and when it is present, the rise in plasma glucose is usually modest. An exception to this may be the diabetic patient [24] who is more likely to develop hyperglycemia. It therefore seems that, before embarking on standardizing the use of insulin therapy immediately following cardiac ischemic events on the premise of preventing hyperglycemia and hyperlipidemia, the metabolic profile of the patients and the clinical care treatment should be documented. Ideally, insulin therapy should only be given on indication of acutely monitored elevated glucose and/or FFA plasma levels. Alternatively, in a subset of each specific group of patients, together with the clinical care treatment given, the metabolic profile is characterized in terms of plasma glucose and FFA levels before a decision is made whether the whole group of patients is treated with insulin therapy. Only when hyperglycemia and hyperlipidemia are present should one use insulin therapy to combat these elevated circulating glucose and FFA levels. 
Table 1 Glucose and free fatty acid (FFA) plasma levels (mM) determined before or during ischemia (pre-reperfusion, pre-R) and at reperfusion of the ischemic cardiac intervention as reported by several different studies

\begin{tabular}{|c|c|c|c|}
\hline Substrate & Pre-reperfusion & Reperfusion & Study \\
\hline Glucose & n.r. & n.r. & pre-reperfusion (pre-R): AMI patients within $24 \mathrm{~h}$ of MI; no \\
\hline FFA & $0.5-2.1$ & n.r. & prior administration of heparin or catecholamines. [14] \\
\hline Glucose & 12 & n.r. & pre-R: AMI-patients selected with arterial FFA levels $>0.8 \mathrm{mM}$ \\
\hline FFA & 1.2 & n.r. & ( $-50 \%$ of MI patients); no heparin used. [15] \\
\hline Glucose & n.r. & n.r. & pre-R: ST-elevation $\mathrm{MI}<12 \mathrm{~h}$ of symptom onset; $\mathbf{R}: 24 \mathrm{~h}$ after \\
\hline FFA & $0.8 \pm 0.4$ & $0.4 \pm 0.2$ & PTCA of the AMI-patients; heparin n.r. [16] \\
\hline Glucose & 7.9 & 6.7 & pre-R: ST-elevation MI $<6 \mathrm{~h}$ of symptom onset; R: $24 \mathrm{~h}$ after \\
\hline FFA & n.r. & n.r. & PTCA/thrombolysis of the AMI patients; heparin n.r. [17] \\
\hline Glucose & $5.9 \pm 0.8$ & $4.4 \pm 0.4$ & pre-R: baseline control dogs; R: 24 h after 3 h LAD occlusion; \\
\hline FFA & $0.4 \pm 0.1$ & $0.8 \pm 0.2$ & heparin n.r., no inotropics. $[18]$ \\
\hline Glucose & $5.7 \pm 1.4$ & not sign. & pre-R: baseline open-chest pigs; R: $30-90$ min after 11 occlusions of $1-2$ \\
\hline FFA & $0.4 \pm 0.2$ & versus pre- $\mathrm{R}$ & min of left main coronary artery; 300 IU/kg heparin, no inotropic. [19] \\
\hline Glucose & $3.8 \pm 0.4$ & $3.7 \pm 0.2$ & pre-R: baseline open-chest pigs; R: $60-90 \mathrm{~min}$ reperfusion after $90 \mathrm{~min}$ \\
\hline FFA & $0.4 \pm 0.1$ & $0.3 \pm 0.1$ & low-flow LAD occlusion; no heparin or inotropics. [20] \\
\hline Glucose & $9.6 \pm 2.4$ & $8.4 \pm 2.0$ & pre-R: before crossclamp in $30 \mathrm{CABG}$ patients; $\mathbf{R}$ : 10 min reperfusion; \\
\hline FFA & $0.4 \pm 0.2$ & $0.4 \pm 0.2$ & $3 \mathrm{mg} / \mathrm{kg}$ heparin, no inotropics $[21]$ \\
\hline Glucose & $5.5 \pm 0.5$ & $6.3 \pm 1.0$ & pre-R: before crossclamp in 21 CABG patients; $\mathbf{R}: 2 \mathrm{~h}$ reperfusion; \\
\hline FFA & $0.4 \pm 0.1$ & $0.4 \pm 0.2$ & no inotropics. $[22,23]$ \\
\hline Glucose & $9.8 \pm 0.2$ & $13.8 \pm 0.3$ & pre-R: before crossclamp in 141 diabetic CABG patients; R: \\
\hline FFA & $0.7 \pm 0.1$ & $0.6 \pm 0.1$ & $6 \mathrm{~h}$ reperfusion; + inotropics. $[24]$ \\
\hline
\end{tabular}

$C A B G$ coronary artery bypass grafting, $A M I$ acute myocardial infarct, $P T C A$ percutaneous transluminal coronary angioplasty, n.r. not reported

\section{Glucose-Insulin therapy and substrate availability}

Because plasma substrate availability may limit metabolism to a large extent [27, 28], any change in substrate availability instigated by insulin therapy will result in shifts in the major cellular metabolic pathways involved in the generation of ATP, i.e., glycolysis and glucose oxidation and fat oxidation. The administration of large amounts of insulin will decrease circulating glucose through activation of GLUT transporters that facilitate cellular glucose uptake and inhibition of hepatic gluconeogenesis. The increased risk of developing temporary periods of hypoglycemia is one of the well-known adverse effects of insulin therapy [29]. Insulin therapy is therefore almost always combined with glucose administration to prevent hypoglycemia. As a result of this increased cellular glucose uptake, glucoseinsulin therapy will increase glycolysis and glucose oxidation. Insulin will also reduce plasma FFA concentrations, resulting in decreased fatty acid oxidation, promotion of TAG storage and possibly hypolipidemia. This lowering of lipids is mainly due to insulin-mediated inhibition of the hormone-sensitive lipase in adipose tissue, the determining enzyme for whole-body lipid fuel availability [30] and insulin-induced CD36-mediated increase in FFA uptake [31]. Interestingly, the developing of hypolipidemia with glucose-insulin therapy has received far less attention in current clinical practice as compared to hypoglycemia [32]. This probably stems from the premise that fatty acids are commonly believed to be elevated at reperfusion and that any decrease in fatty acid metabolism is always associated with improved cardiac recovery from ischemia. However, we now know that hyperlipidemia is not always present at reperfusion (see above), and that too little fatty acid oxidation can be detrimental for cardiac recovery (see below). In the following paragraphs, the insulin-mediated changes in the three major ATP-generating pathways (increased glycolysis, increased glucose oxidation, decreased fatty acid oxidation) are discussed in relation to cardiac recovery from ischemia. It is well documented that the potential usefulness of GIK certainly also leads to non-metabolic mechanisms such as the activation of cell survival pathways leading to cardioprotection through reduction in apoptosis [33-36] and reduced inflammatory (22) and neurohumoral responses (11). However, in this review we focus primarily on the GIK effects on plasma substrate levels and metabolic pathways.

\section{Increased glycolysis}

The non-oxidative breakdown of glucose to pyruvate or lactate, i.e. glycolysis, is commonly increased in the postischemic heart [37-39]. In addition, important cardiac pathologies such as hibernation, hypertrophy and heart failure are associated with increased glycolytic activity, probably as a result of recurrent episodes of limited oxygen supply [40-42]. The use of glucose-insulin therapy will 
further enhance post-ischemic glycolysis, provided that hypoglycemia does not occur. The functional benefit of increased glycolysis is in keeping with the observation that the heart requires glycolysis during early reperfusion [43, 44]. Although glycolytically produced ATP only amounts to $-2 \%$ of total ATP production in the presence of oxygen, this ATP seems to be preferentially used for membrane functions allowing recovery of ionic homeostasis (preventing $\mathrm{Ca}^{2+}$ overload) during early reperfusion. In addition, acidification at the moment of reperfusion may be beneficial, because it inhibits mitochondrial permeability transition pore opening [45].Thus, increased glycolysis during reperfusion is protective in conditions of recurrent ischemia and reperfusion. However, increased glycolytic flux during zero-flow ischemia is detrimental [46] and may result in increased acidification during ischemia. Finally, the postischemic increase in glycolysis will also slow down cellular energy transfer [47-49] and may decrease the rate of maximal, sustainable oxidative phosphorylation [50, 51].

It therefore seems that increasing glycolysis during reperfusion with glucose-insulin therapy will protect against reperfusion damage at the expense of slower energy transfer. Because it is unlikely that delayed energy transfer will be detrimental for the heart during acute reperfusion, increasing glycolysis during reperfusion seems to entail an overall protective effect against reperfusion damage.

\section{Increased glucose oxidation}

Although increased glucose oxidation is not always observed following ischemia [27, 37, 52], most studies have shown that the activation of glucose oxidation in the reperfusion phase improves the recovery of cardiac performance [53, 54]. Thus glucose-insulin therapy will be beneficial through activation of this pathway, provided that no hypoglycemia occurs that may actually decrease glucose oxidation. In addition, the therapy will reduce hyperglycemia, a risk factor that has been shown to contribute independently to poor recovery [55].

Currently, the two most prevailing hypotheses explaining the protection offered by increased glucose oxidation involves increased mechanical efficiency and decreased proton load, respectively. With respect to the former, it has recently been shown that oxygen consumption for the same amount of work increased considerably (from 10\% at high work to $48 \%$ at unloading conditions) when switching from a predominantly glucose metabolizing condition to a predominantly fatty acid metabolizing condition in in vivo pigs [56]. This decreased efficiency with increased fatty acid oxidation may be explained by a fatty acid induced decreased P:O ratio in addition to uncoupling of oxidative consumption and futile, energy-consuming cycling of fatty acids in and out the intracellular triglyceride pool [56]. The second hypothesis is associated with the so-called coupling of glycolysis with glucose oxidation, i.e. when pyruvate produced by glycolysis is subsequently oxidized in the TCA cycle, the proton production from hydrolysis of glycolytically-produced ATP is zero [27]. However, if glycolysis is uncoupled from glucose oxidation, and pyruvate is not oxidized further, there is a net production of two protons from each glucose molecule metabolized. Such may occur with increased fatty acid metabolism. Fatty acids inhibit glucose oxidation more than glycolysis and glycolysis more than glucose uptake, indicating that with increasing fatty acid oxidation the rate of glycolysis increasingly deviates from that of glucose oxidation, resulting in the uncoupling of glycolysis from glucose oxidation [57]. The resulting acidosis may then cause decreased contractility and increased calcium overload during the reperfusion period. Increased glucose oxidation will then prevent ongoing acidosis during the early reperfusion period, thereby improving recovery of mechanical performance. However, this theory is not without controversy. It has been shown that insulin-glucose administration in an isolated heart model improved functional recovery compared with the administration of dichloroactetae (DCA) which is a direct stimulant of carbohydrate oxidation, whereas DCA had a greater impact on increasing glucose oxidation [58]. In that study it was found that the protection was not associated with increased coupling of glucose oxidation to glycolysis. A recent study examining mechanical recovery following low-flow ischemia in GLUT1overexpressed mice hearts reached similar conclusions [59]. An uniform mechanistic, cellular, explanation for the advantageous effects of increasing glucose oxidation is therefore currently lacking.

In general, the literature suggests that treatment aimed at stimulation of glucose oxidation while normoglycemia is maintained (i.e. without the concomitant development of hyperglycemia or hypoglycemia) seems to be promising and safe with respect to improved cardiac function in the post-ischemic period.

\section{Decreased fatty acid oxidation}

At the moment, the prevailing opinion is that increased fatty acid oxidation during the reperfusion period is detrimental to the functional recovery of the heart. However, although some studies demonstrate that increasing FA oxidation is associated with decreased functional recovery in the reperfusion phase $[57,60,61]$ other studies showed unaltered [62] or even improved recovery with increased FA oxidation [37, 63]. It has been suggested that the effects of lipids are primarily detrimental when present at high levels during the ischemic period, but not during reperfusion [64]. That FA oxidation during reperfusion can 
be protective is also supported by studies showing decreased functional recovery of hearts from fatty acid transporterknockout animals that lack the sarcolemmal fatty acid transporter CD36 [65], a similar observation as found for GLUT4-knockout animals [66]. Recently, Tuunanen et al [67] demonstrated that acute depression of plasma FFA by acipimox, an inhibitor of lipolysis, depressed cardiac work in healthy and diseased humans with additional decreases in cardiac efficiency for heart failing patients. Acipimox decreased FFA concentrations from $0.6 \mathrm{mM}$ to $0.1 \mathrm{mM}$. Interestingly, the very few studies examining the effect of insulin therapy on FFA levels also indicate that this therapy may reduce FFA to similar levels. Addo et al [16] reported FFA levels of $0.2 \mathrm{mM}$ with GIK therapy in patients undergoing primary percutaneous coronary intervention (without taking into account sample lipolysis). We recently demonstrated FFA levels around $0.1 \mathrm{mM}$ with insulin therapy following CABG procedures [23]. These low FFA levels are commensurate with the observation that FFA concentrations are often not increased during reperfusion (see "Plasma substrate availability during cardiac ischemic events" section above). From these observations it may be hypothesized that there exists a requirement for a minimal concentration of plasma FFA for the heart in order to perform optimally. As for glucose, the data suggest that the prevention of hypolipidemia as well as hyperlipidemia during reperfusion may be an important consideration of any metabolic therapy, including the glucose-insulin therapy.

Finally, one complicating factor concerning FA effects that may explain some of the controversy is that there are "good" and "bad" fatty acids. Especially the saturated fatty acids such as palmitate appear to be detrimental, even inducing apoptosis [68], whereas other fatty acids (mainly (poly)unsaturated fatty acids) appear to be beneficial in the reperfusion period [69]. Future preclinical studies have to demonstrate the potential beneficial effect of the combination of glucose-insulin therapy with additional lipids on myocardial energy balance, infarct size and mechanical function following ischemia and reperfusion. Due to the ambiguity of the cardiac functional effects of changes in FA metabolism, clinically directed manipulation of FA metabolism must be executed with great care.

\section{Summary}

In the peri-operative patient, the standard clinical treatment and applied biochemical determination of especially plasma FFA are critical issues when reviewing substrate levels during reperfusion. Each surgical team should determine the metabolic consequences of its perioperative protocol to determine if improvement in cardiac function may be anticipated with the use of metabolic support. FFA levels are most likely to be elevated during conditions of acute coronary syndromes in the conscious state (e.g. acute MI) and less so during reperfusion post CABG. Consequently, GIK therapy in conditions of CABG may result in hypolipidemia that can potentially limit the beneficial effects of this therapy. Whether hypolipidemia is disadvantageous during post $\mathrm{CABG}$ reperfusion awaits further pre-clinical and subsequently clinical studies. At the moment, monitoring of FFA levels during GIK therapy, as is commonly performed for glucose levels, is strongly recommended.

From a clinical point of view, a strategy directed at monitoring and thereafter maintaining plasma substrate levels in the normal range for (glucose 4-6 mM; FFA 0.2-0.6 mM), and at stimulation of glucose oxidation, seems to hold the most promise for optimal metabolic reperfusion treatment following cardiac ischemic episodes.

Acknowledgement Supported in part by The Netherlands Heart Foundation Grant \# 2001B107.

Open Access This article is distributed under the terms of the Creative Commons Attribution Noncommercial License which permits any noncommercial use, distribution, and reproduction in any medium, provided the original author(s) and source are credited.

\section{References}

1. Sodi-Pallares D, Testelli M, Fishleder F. Effects of intravenous infusion of a potassium-insulin-glucose solution on the electrographic signs of myocardial infarction. Am J Cardiol. 1962;9:166-81.

2. Opie LH. The heart physiology, from cell to circulation. 3rd ed. Philadelphia, New York: Lippincott-Raven; 1998. p. 297.

3. Cahill GF. Starvation in man. New Engl J Med. 1970;282:668-75.

4. Zuurbier CJ, Keijzers PJM, Koeman A, Van Wezel HB, Hollmann MW. Anesthesia's effects on plasma glucose and insulin and cardiac hexokinase at similar hemodynamics and without major surgical stress in the fed rat. Anesth Analg. 2008;106:135-42.

5. Persson E, Norderstrom J, Nilsson-Ehle P, Hagenfeldt L, Wahren J. Plasma lipolytic activity and substrate oxidation after intravenous administration of heparin and a low molecular weight heparin fragment. Clin Pharmacol. 1990;10:573-83.

6. Malmstrom R, Packard CJ, Caslake M, Bedford D, Stewart P, Shephard J, Tuskinen MR. Effect of heparin-stimulated plasma lipolytic activity on VLDL apo B subclass metabolism in normal subjects. Atherosclerosis. 1999;146:381-90.

7. Grossman MI, Moeller HC, Palm L. Effect of lipemia and heparin on free fatty acid concentration of serum in humans. Proc Soc Exp Biol Med. 1955;90:106-9.

8. Visser L, Zuurbier CJ, van Wezel HB, van der Vusse GJ, Hoek FJ. Overestimation of plasma nonesterified fatty acid concentrations in heparinized blood. Circulation. 2004;110:e328.

9. Krebs M, Stingl H, Nowotny P, Weghuber D, Bischof M, Waldhausl W, et al. Prevention of in vitro lipolysis by tetrahydrolipstatin. Clin Chem. 2000;46:950-4.

10. Widmer IE, Puder JJ, Konig C, Pargger H, Zerkowski HR, Girard $\mathrm{J}$, et al. Cortisol response in relation to the severity of stress and illness. J Clin Endocrinol Metabol. 2005;90:4973-4. 
11. Van Wezel HB, Zuurbier CJ, de Jonge E, van Dam EWCM, van Dijk J, Endert E, et al. Differential effects of a perioperative hyperinsulinemic normoglycemic clamp on the neurohumoral stress response during coronary artery surgery. J Clin Endocrinol Metab. 2006;91:4144-53.

12. Oliver MF. Metabolic causes and prevention of ventricular fibrillation during acute coronary syndromes. Am J Med. 2002;112:305-11.

13. Neely JR, Morgan HE. Relationship between carbohydrate and lipid metabolism and the energy balance of the heart muscle. Annu Rev Physiol. 1974;36:413-59.

14. Oliver MF, Kurien VZ, Greenwood TW. Relation between serum free fatty acids and arrhythmias and death after acute myocardial infarction. Lancet. 1968;1:710-5.

15. Mueller HS, Ayres SM. Metabolic response of the heart in acute myocardial infarction in man. Am J Cardiol. 1978;42:363.

16. Addo TA, Keeley EC, Cigarroa JE, Lange RA, de Lemos JA, Dobbins RL, et al. Effect of glucose-insulin-potassium on plasma free fatty acid concentrations in patients undergoing primary percutaneous coronary intervention for ST-elevation in myocardial infarction. Am J Cardiol. 2004;94:1288-9.

17. Goyal A, Mahaffey KW, Garg J, Nicolau JC, Hochman JS, Weaver $\mathrm{WD}$, et al. Prognostic significance of the change in glucose levels in the first $24 \mathrm{~h}$ after acute myocardial infarction: results from the CARDINAL study. Eur Heart J. 2006;27:1289-97.

18. Schwaiger M, Neese RA, Araujo L, Wyns W, Wisneski JA, Sochor $\mathrm{H}$, et al. Sustained nonoxidative glucose utilization and depletion of glycogen in reperfused canine myocardium. J Am Coll Cardiol. 1989;13:745-54.

19. Korvald C, Elvenes OP, Aghajani E, Myhre ES, Myrmel T. Postischemic mechanoenergetic inefficiency is related to contractile dysfunction and not altered metabolism. Am J Physiol Heart Circ Physiol. 2001;281:H2645-53.

20. Zhu P, Lu L, Xu Y, Greyson C, Schwartz GG. Glucose-insulinpotassium preserves systolic and diastolic function in ischemia and reperfusion in pigs. Am J Physiol Heart Circ Physiol. 2000;278:H595-603.

21. Pietersen HG, Langenberg CJM, Geskes G, Kester A, de Lange S, Van der Vusse GJ, et al. Myocardial substrate uptake and oxidation during and after routine cardiac surgery. J Thorac Cardiovasc Surg. 1999;118:71-84.

22. Visser L, Zuurbier CJ, Hoek FJ, Opmeer BC, de Jonge E, de Mol BAJM, et al. Glucose, insulin and potassium applied as perioperative hyperinsulinaemic normoglycaemic clamp: effects on inflammatory response during coronary artery surgery. $\mathrm{Br} \mathrm{J}$ Anesth. 2005;95:448-57.

23. Zuurbier CJ, Hoek F, Van Dijk J, Van Wezel HB. Hyperinsulinemic normoglycemic clamp results in hypolipidemia during coronary artery surgery. J Mol Cell Cardiol. 2007;42:s55. Abstract.

24. Lazar HL, Chipkin SR, Fitzgerald CA, Bao Y, Cabral H, Apstein CS. Tight glycemic control in diabetic coronary artery bypass graft patients improves perioperative outcomes and decreases recurrent ischemic events. Circulation. 2004;104:1497-502.

25. Bellodi G, Manicardi V, Malavasi V, Veneri L, Bernini G, Bossini $\mathrm{P}$, et al. Hyperglycemia and prognosis of acute myocardial infarction in patients without diabetes mellitus. Am J Cardiol 1989;64:885-8.

26. Van den Berghe G, Wouters R, Weekers F, Verwaest C, Bruyninckx F, Schetz $\mathrm{M}$, et al. Intensive insulin therapy in critically ill patients. N Engl J Med. 2001;345:1359-67.

27. Lopaschuk GD, Wambolt RB, Barr RL. An imbalance between glycolysis and glucose oxidation is a possible explanation for the detrimental effects of high levels of fatty acids during aerobic reperfusion of ischemic hearts. J Pharmacol Exp Ther. 1993;264:135-44.
28. Longnus SL, Wambolt RB, Barr RL, Lopaschuk GD, Allard MF. Regulation of myocardial fatty acid oxidation by substrate supply. Am J Physiol Heart Circ Physiol. 2001;281:H1561-7.

29. Clayton SB, Mazur JE, Condren S, Hermayer KL, Strange C. Evaluation of an intensive insulin protocol for septic patients in a medical intensive care unit. Crit Care Med. 2006;34:2974-8.

30. Coppack SW, Jensen MD, Miles JM. In vivo regulation of lipolysis in humans. J Lip Res 1994;35:177-93.

31. Bonen A, Han XX, Habets DD, Febbraio M, Glatz JF, Luiken JJ. A null mutation in skeletal muscle FAT/CD36 reveals its essential role in insulin- and AICAR-stimulated fatty acid metabolism. Am J Physiol Endocrinol Metab. 2007;292:E1740-49.

32. Tian R, Balschi JA. Interaction of insulin and AMPK in the ischemic heart. Another chapter in the book of metabolic therapy. Circ Res. 2006;99:3-5.

33. Hausenloy DJ, Yellon DM. Reperfusion injury salvage kinase signalling: taking a RISK for cardioprotection. Heart Fail Rev. 2007;12:217-34.

34. Matsui T, Li L, del Monte F, Fukui Y, Franke TF, Hajjar RJ, Rosenzweig A. Adenoviral gene transfer of activated phosphatidylinositol 3c-kinase and Akt inhibits apoptosis of hypoxic cardiomyocytes in vitro. Circulation. 1999;100:2373-9.

35. Gottlob K, Majewski N, Kennedy S, Kandel E, Robey RB, Hay $\mathrm{N}$. Inhibition of early apoptotic events by Akt/PKB is dependent on the first committed step of glycolysis and mitochondrial hexokinase. Genes Dev. 2001;15:1406-18.

36. Zuurbier CJ, Eerbeek O, Meijer AJ. Ischemic preconditioning, insulin, and morphine all cause hexokinase redistribution. Am J Physiol Heart Circ Physiol. 2005;289:H496-9.

37. Montessiut C, Papageorgiou I, Tardy-Cantalupi I, Rosenblatt-Velin N, Lerch R. Postischemic recovery of heart metabolism and function: role of mitochondrial fatty acid transfer. J Appl Physiol. 2000;89:111-9.

38. McNulty PH, Jagasia D, Cline GW, Ng CK, Whiting JM, Garg P, et al. Persistent changes in myocardial glucose metabolism in vivo during reperfusion of a limited-duration coronary occlusion. Circulation. 2000;101:917-22.

39. Myears DW, Sobel BE, Bergmann SR. Substrate use in ischemic and reperfused canine myocardium. Quantitative considerations. Am J Physiol Heart Circ Physiol. 1987;253:H107-H114.

40. Sack MN, Kelly DP. The energy substrate switch during development of heart failure: gene regulatory mechanisms. Int J Mol Med. 1998;1:17-24.

41. Rosenblatt-Velin N, Montessuit C, Papageorgio I, Terrand J, Lerch $R$. Post infarction heart failure in rats is associated with upregulation of GLUT1 and downregulation of genes of fatty acid metabolism. Cardiovasc Res. 2001;52:407-16.

42. Laussmann T, Janosi RA, Fingas CD, Schlieper GR, Schlack W, Schrader J, et al. Myocardial protein analysis reveals reduced NOS inhibition and enhanced glycolytic capacity in areas of low local blood flow. FASEB J. 2002;16:628-30.

43. Jeremy RW, Koretsune Y, Marban E, Becker LC. Relation between glycolysis and calcium homeostasis in postischemic myocardium. Circ Res. 1992;70:1180-90.

44. Jeremy RW, Ambrosio G, Pike MM, Jacobus WE, Becker LC. The functional recovery of postischemic myocardium requires glycolysis during early reperfusion. J Mol Cell Cardiol. 1993;25:261-76.

45. Cohen MV, Yang XM, Downey JM. The $\mathrm{pH}$ hypothesis of postconditioning: staccato reperfusion reintroduces oxygen and perpetuates myocardial acidosis. Circulation. 2007;115:1895903.

46. Cross HR, Opie LH, Radda GK, Clarke K. Is a high glycogen content beneficial or detrimental to the ischemic heart? A controversy resolved. Circ Res. 1996;78:482-91.

47. Zuurbier CJ, Ince C. Postischemic changes in the response time of oxygen consumption to demand in the isolated rat heart are 
mediated partly by calcium and glycolysis. Pflügers Arch. 2002;443:908-16.

48. Zuurbier CJ, Van Beek JHGM. Mitochondrial response to heart rate steps in isolated rabbit heart is slowed after myocardial stunning. Circ Res. 1997;81:69-75.

49. Harrison GJ, van Wijhe H, de Groot B, Dijk FJ, Gustafson LA, Van Beek JHGM. Glycolytic buffering affects cardiac bioenergetic signaling and contractile reserve similar to creatine kinase. Am J Physiol Heart Circ Physiol. 2003;285:H883-90.

50. Kobayashi K, Neely JR. Control of maximum rates of glycolysis in rat cardiac muscle. Circ Res. 1979;44:166-75.

51. Conley KE, Kemper WF, Crowther GJ. Limits to sustainable muscle performance interaction between glycolysis and oxidative phosphorylation. J Exp Biol. 2001;204:3189-94.

52. Schöder H, Knight RJ, Kofoed KF, Schelbert HR, Buxton DB. Regulation of pyruvate dehydrogenase activity and glucose metabolism in post-ischemic myocardium. Biochim Biophys Acta. 1998;1406:62-72.

53. McVeigh JJ, Lopaschuk GD. Dichloroacetate stimulation of glucose oxidation improves recovery of ischemic rat hearts. Am J Physiol. 1990;259:H1079-85.

54. Lewandowski ED, White LT. Pyruvate dehydrogenase influences post ischemic heart function. Circulation. 1995;91:2071-9.

55. Su H, Sun X, Ma H, Zhang H, Yu Q, Huang C, et al. Acute hyperglycemia exacerbates myocardial ischemia/reperfusion injury and blunts cardioprotective effect of GIK. Am J Physiol Endocrinol Metab. 2007;293:E629-35.

56. Korvald C, Elvenes OP, Myrmel T. Myocardial substrate metabolism influences left ventricular energetics in vivo. Am J Physiol Heart Circ Physiol. 2000;278:H1345-51.

57. Terrand J, Papageorgio I, Rosenblatt-Velin N, Lerch R. Calciummediated activation of pyruvate dehydrogenase in severely injured postischemic myocardium. Am J Physiol Heart Circ Physiol. 2001;281:H722-30.

58. Wang P, Lloyd SG, Chatham JC. Impact of high glucose/high insulin and dichloroacetate treatment on carbohydrate oxidation and functional recovery after low-flow ischemia and reperfusion in the isolated rat heart. Circulation. 2005;111:2066-72.
59. Luptak I, Yan J, Cui L, Jain M, Liao R, Tian R. Long-term effects of increased glucose entry on mouse hearts during normal aging and ischemic stress. Circulation. 2007;116:901-9.

60. Kudo N, Barr AJ, Barr RL, Desai S, Lopaschuk GD. High rates of fatty acid oxidation during reperfusion of ischemic hearts are associated with a decrease in malonyl-CoA levels due to an increase in 5фAMP-activated protein kinase inhibition of acetyl CoA carboxylase. J Biol Chem. 1995;270: 17513-20.

61. Liu Q, Docherty JC, Rendell JCT, Clanachan AS, Lopaschuk GD. High levels of fatty acids delay recovery of intracellular $\mathrm{pH}$ and cardiac efficiency in post-ischemia hearts by inhibiting glucose oxidation. J Am Coll Cardiol. 2002;39:718-25.

62. Liedtke AJ, DeMaison L, Eggleston AM, Coken LM, Nellis SH. Changes in substrate metabolism and effects of excess fatty acids in reperfused myocardium. Circ Res. 1988;62:535-42.

63. Van de Velde M, Wouters PF, Rolf N, Van Aken H, Flameng W, Vandermeersch E. Long chain triglycerides improve recovery from myocardial stunning in conscious dogs. Cardiovasc Res. 1996;32:1008-15.

64. Van de Velde M, DeWolf M, Leather HA, Wouters PF. Effects of lipids on the functional and metabolic recovery from global myocardial stunning in isolated rabbit hearts. Cardiovasc Res. 2000;48:129-37.

65. Brinkman JF, Abumrad NA, Ibrahimi A, van der Vusse GJ, Glatz JF. New insights into long-chain fatty acid uptake by heart muscle: A crucial role for fatty acid translocase/CD36. Biochem J 2002;367:561-70.

66. Tian R, Abel ED. Responses of GLUT4 deficient hearts to ischemia underscores the importance of glycolysis. Circulation. 2001;103:2961-6.

67. Tuunanen H, Engblom E, Naum A, Nagren K, Hesse B, Airaksinen KEJ, et al. Free fatty acid depletion acutely decreases cardiac work and efficiency in cardiomyopathic heart failure. Circulation. 2006;114:2130-7.

68. Listenberger LL, Ory DS, Schaffer JE. Palmitate-induced apoptosis can occur through a ceramide independent pathway. J Biol Chem. 2001;276:14890-5

69. O'Neill S. Cardiac Ca2+ regulation and the tuna fish sandwich. News Physiol Sci. 2002;17:162-5. 